\title{
PRODUÇÃO DE ÁCIDOS GRAXOS LIVRES A PARTIR DE ÓLEO DE SOJA NOS MODOS BATELADA E BATELADA ALIMENTADA POR UMA LIPASE COMERCIAL EM BANHO DE ULTRASSOM
}

\author{
M. C. P. ZENEVICZ ${ }^{1}$, M. C. FEITEN ${ }^{1}$, C. DALLA ROSA ${ }^{2}$, D. de OLIVEIRA ${ }^{1}$, J. V. de \\ OLIVEIRA $^{1}$ \\ ${ }^{1}$ Universidade Federal de Santa Catarina, Departamento de Engenharia Química e de \\ Alimentos \\ ${ }^{2}$ UFFS - Universidade Federal Fronteira Sul, Departamento de Engenharia Ambiental \\ E-mail para contato: mirianfeiten@hotmail.com
}

\begin{abstract}
RESUMO - A hidrólise de triacilgliceróis é a principal reação para produção de ácidos graxos livres (AGL). Este trabalho teve por objetivo propor uma nova tecnologia para a produção enzimática de ácidos graxos livres a partir de óleo de soja, em sistema livre de solvente, nos modos batelada e batelada alimentada, em banho de ultrassom, empregando a lipase comercial Lipozyme TL IM. Foram realizados estudos cinéticos na razão molar óleo:água de 1:9, 100\% da potência do ultrassom $(132 \mathrm{~W})$, temperatura de $65^{\circ} \mathrm{C}$, agitação mecânica de $600 \mathrm{rpm}$ e $10 \%$ de enzima. Também foram realizadas cinéticas sem o emprego do ultrassom a fim de investigar o efeito do mesmo. A acidez das amostras foi quantificada pelo método IUPAC 2.201, através de titulação com KOH 0,1M. Na hidrólise enzimática conduzida em modo batelada, foram obtidas conversões na ordem de $89 \%$ em 2 horas de reação quando o ultrassom foi empregado, enquanto que na ausência do ultrassom estes índices foram atingidos em 4 horas de reação. Nas reações de hidrólise enzimática realizadas no modo batelada alimentada $(0,068$ $\mathrm{mL} / \mathrm{min}$ ), não houve grande influência do ultrassom nas conversões em AGL, que ficaram em torno de $90 \%$.
\end{abstract}

\section{INTRODUÇÃO}

A tecnologia enzimática é hoje um dos campos mais promissores dentro das novas tecnologias para síntese de compostos de alto valor agregado. As enzimas, além de serem atrativas e versáteis, catalisam uma série de transformações de modo seletivo, rápido e em condições brandas de reação, o que as difere dos catalisadores não enzimáticos. A grande vantagem das enzimas é que elas catalisam as transformações moleculares sem ocorrência de reações paralelas, devido a sua especificidade (Dziezak, 1991; Patel, 2002; Pizarro e Park, 2003).

Atualmente, as lipases têm apresentado grande importância no cenário biotecnológico. Essas enzimas representam uma perspectiva de desenvolvimento nos processos para obtenção de mono e diacilgliceróis, ácidos graxos, agentes biotensoativos, compostos de aroma e sabor 
e lipídios estruturados ou modificados (Treichel et al., 2010). A hidrólise enzimática é uma alternativa aos métodos convencionais e vem sendo empregada com sucesso em sistemas livres de solvente. Nestes sistemas biocatalisados, as reações ocorrem na interface entre as fases aquosa e oleosa (Ramachandran et al., 2006).

O emprego de ultrassom é um método reconhecidamente eficaz para a redução de tamanho de partículas. Esta técnica pode gerar partículas nanoscópicas em suspensões, dispersões e emulsões e, além disso, acelerar reações químicas e bioquímicas através da maior facilidade da mistura dos reagentes e aumento nas taxas de difusão, entre muitas outras (Kuldiloke, 2002). A irradiação por ultrassom pode ser um método alternativo para reduzir as limitações de transferência de massa substrato-enzima, assim como pode proporcionar mudanças conformacionais na estrutura de proteínas. O efeito físico do ultrassom em processos biotecnológicos consiste principalmente na alteração da temperatura e pressão do micro-ambiente em função do efeito cavitacional (Babicz, 2009).

Com base nestes aspectos, o objetivo principal deste trabalho foi investigar a hidrólise de óleo de soja pela lipase comercial Lipozyme TL IM em sistema de ultrassom.

\section{MATERIAL E MÉTODOS}

O substrato da reação de hidrólise utilizado neste trabalho foi o óleo de soja refinado adquirido da BUNGE. A lipase comercial imobilizada Lipozyme TL IM foi adquirida da Novozymes Brasil. Solvente n-hexano (Cinética) foi utilizado na filtração do óleo hidrolisado para remoção da enzima. Uma solução de fenolftaleína (Nuclear) foi utilizada como indicador para as medidas de acidez do óleo. Etanol e éter etílico (Vetec) foram utilizados no processo de medição. $\mathrm{KOH}$ (Vetec) 0,1M foi utilizado na determinação da acidez. Solução de Karl Fisher (Merck) foi utilizada na determinação do teor de água das amostras, realizada através de equipamento de Karl Fisher (modelo DL 50, Mettler Toledo).

\subsection{Procedimento Experimental}

As reações de hidrólise enzimática do óleo de soja no modo batelada foram conduzidas em um erlenmeyer de $50 \mathrm{ml}$. Para cada experimento, eram pesados 18 gramas de óleo e aproximadamente 3,34 gramas de água destilada (razão 1:9 molar) e a quantidade adicionada de enzima $(10 \mathrm{~m} / \mathrm{m} \%)$ era calculada sobre a massa total dos substratos. A mistura reacional era deixada sob agitação de $600 \mathrm{rpm}$ (agitador mecânico modelo RW 20 D, IKA) em banho de ultrassom (modelo USC 1800A, UNIQUE - frequência de $40 \mathrm{~kW}$ e potência máxima de $132 \mathrm{~W}$ ) durante o tempo reacional previamente definido. As reações de hidrólise foram conduzidas em $100 \%$ da potência do ultrassom $(132 \mathrm{~W})$ e temperatura de $65^{\circ} \mathrm{C}$. A fim de se investigar o efeito do ultrassom na conversão de ácidos graxos livres, também foram realizadas cinéticas sem o emprego do mesmo. As mesmas condições reacionais e procedimentos foram seguidos para as subsequentes reações em modo batelada alimentada, exceto pelo fato que, foi calculada a taxa de evaporação de água, identificada através das análises em Karl Fisher, e esta quantidade de água era adicionada a cada minuto durante o 
tempo reacional, através de um pipetador automático. A Figura 1 mostra o aparato experimental utilizado nos experimentos de hidrólise.

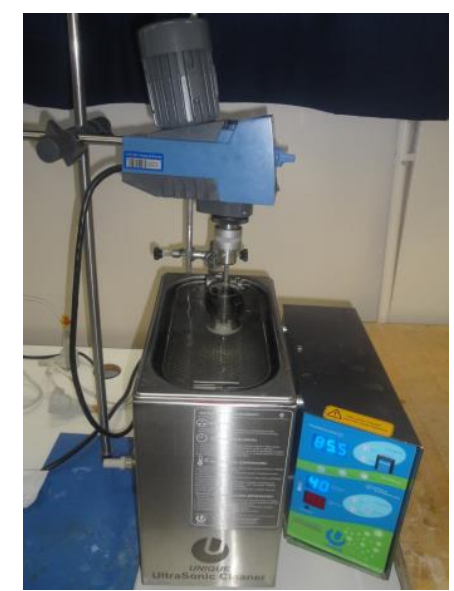

Figura 1 - Aparato experimental das reações de hidrólise enzimática.

\subsection{Quantificação da Acidez}

A determinação dos ácidos graxos livres (AGL) nas amostras foi realizada por titulação com KOH, segundo o método IUPAC 2.201. Aproximadamente 3 gramas de óleo e 3 gotas de solução de fenolftaleína foram diluídas em $50 \mathrm{~mL}$ de uma solução 1:1 etanol:éter (v/v). Esta solução foi titulada com uma solução de $\mathrm{KOH} 0,1 \mathrm{M}$, sob agitação vigorosa até mudança súbita de coloração branca para rosa. A acidez do óleo foi calculada de acordo com a Equação (1):

$$
\boldsymbol{A}(\boldsymbol{m} / \boldsymbol{m}, \%)=\frac{V \times M_{K O H} \times P M_{T A G}}{10 \times m_{a}}
$$

Onde: V: volume da solução de KOH utilizado na titulação (mL)

$\mathrm{M}_{\mathrm{KOH}}$ : molaridade da solução de $\mathrm{KOH}$ (mol/L)

$\mathrm{PM}_{\mathrm{TAG}}$ : Peso molecular médio dos triacilgliceróis presentes no óleo

$\mathrm{m}_{\mathrm{a}}$ : massa da amostra $(\mathrm{g})$

\section{RESULTADOS E DISCUSSÃO}

A Figura 2 (a) e (b) mostra as cinéticas realizadas nos modos batelada e batelada alimentada, respectivamente, com e sem a influência do ultrassom, para a hidrólise do óleo de soja pela Lipozyme TL IM. A taxa de evaporação de água encontrada por titulação em Karl Fisher de $0,068 \mathrm{~mL} / \mathrm{min}$ foi adicionada no decorrer das reações na batelada alimentada. 

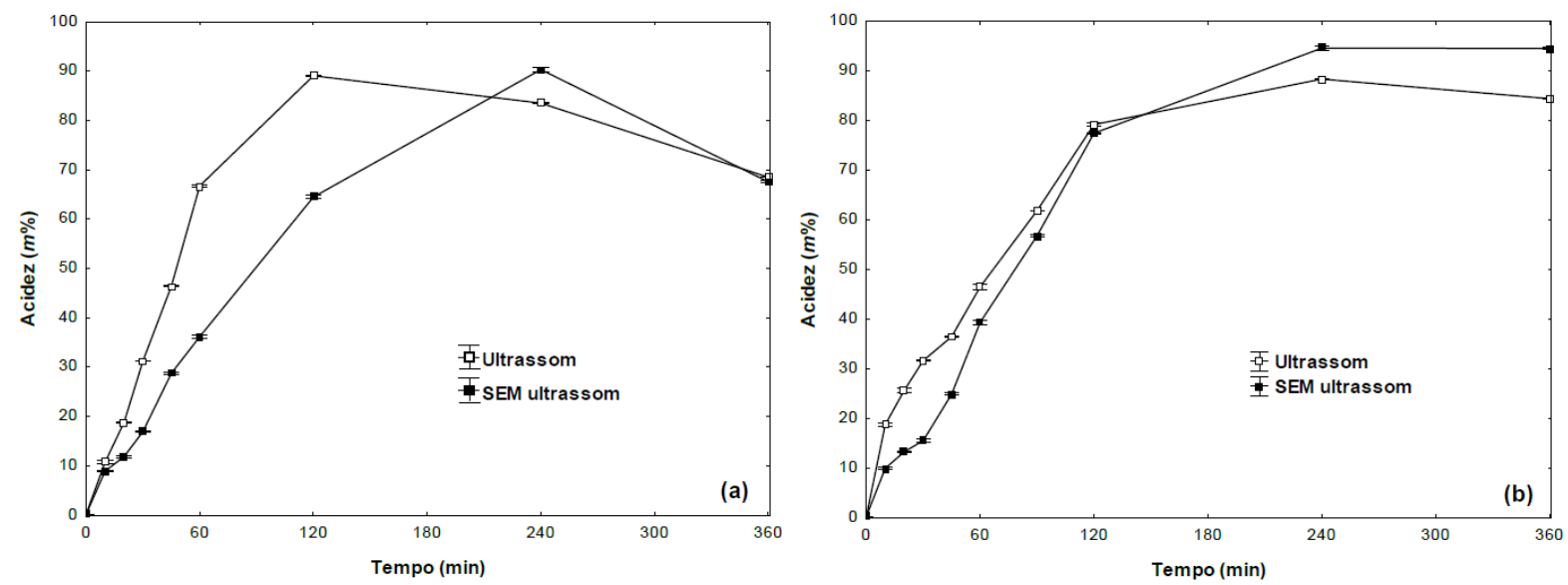

Figura 2 - Hidrólise de óleo de soja catalisada pela Lipozyme TL IM, com e sem emprego de ultrassom, por (a) batelada (velocidades iniciais de reação, $\mathrm{r}\left(\mathrm{min}^{-1}\right)$ de 1,07 e 0,56, respectivamente) e (b) batelada alimentada $(0,068 \mathrm{~mL} / \mathrm{min})$ (velocidades iniciais de reação, $\mathrm{r}$ $\left(\min ^{-1}\right)$ de 0,72 e 0,63, respectivamente). Condições experimentais: razão molar 1:9, $10 \%$ de enzima, $600 \mathrm{rpm}$, potência de $100 \%, 65^{\circ} \mathrm{C}$.

Na Figura 2 (a) pode-se observar que foram alcançadas conversões de 89\% após 2 horas de reação com emprego de ultrassom. Pode-se concluir que na batelada sem ultrassom a reação de hidrólise é mais lenta $\left(\mathrm{r}=0,56 \mathrm{~min}^{-1}\right)$, corroborando com a teoria das emulsões e mostrando que o ultrassom reduz as limitações de transferência de massa, melhorando a agitação molecular e, consequentemente, aumentando a área interfacial para a enzima estar agindo. A conversão alcançada com ultrassom em 2 horas é atingida em 4 horas sem irradiação ultrassônica. Provavelmente, para o sistema reacional estudado, as limitações de transferência de massa estão sendo vencidas pelo simples emprego da agitação mecânica. A partir de 4 horas de reação as conversões começam a diminuir, provavelmente por restrições de substrato (evaporação da água).

Abismail et al. (1999) relataram que as emulsões óleo/água formadas por ultrassom são bastante estáveis e podem perdurar por dias. Portanto, o uso do ultrassom durante todo o período reacional com intuito de gerar emulsões pode vir a ser desnecessário, uma vez que, após certo período de exposição às ondas ultrassônicas, as emulsões formadas permaneceriam estáveis por um longo período de tempo. Estes autores também mostraram que, para misturas com grande porcentagem de óleo (>50\% v/v), a taxa de desestabilização das emulsões com o passar do tempo se torna significante, mesmo quando estas são formadas pelo uso do ultrassom. Cabe ressaltar que os autores estudaram o sistema querosene/água, mas considerando que este resultado pode ser estendido ao sistema óleo de soja/água aqui estudado, o declínio na taxa de reação com o passar do tempo pode estar relacionado com a desestabilização das emulsões formadas pelo ultrassom.

Awadalak (2012) identificou altas taxas de evaporação de água, acima de $33 \%$ em 4 horas, quando empregou sonda ultrassônica na emulsificação de óleo de palma a $55^{\circ} \mathrm{C}$, para posterior reação de hidrólise catalisada por Lipozyme RM IM. Quando expôs a mistura reacional somente 3 minutos à sonda para formação da emulsão como etapa prévia à reação 
de hidrólise, suas conversões aumentaram cerca de 5 vezes frente à mesma reação de hidrólise assistida pela sonda (50 e 10\%, respectivamente).

Pode-se observar na Figura 2 (b) que quando a água é adicionada no decorrer da reação, a cinética é um pouco mais lenta $\left(\mathrm{r}=0,72 \mathrm{~min}^{-1}\right)$, mas atinge os mesmos $88 \%$ após 4 horas de reação, sem grandes quedas na conversão em 6 horas. Pode-se observar também que o emprego do ultrassom não tem grande influência nas conversões das reações de hidrólise na batelada alimentada.

Liu et al. (2008) compararam a hidrólise de óleo de soja usando lipase de Candida lipolytica, em sistema de ultrassom (potência de $1,64 \mathrm{~W} / \mathrm{cm}^{2}$, temperatura de $50{ }^{\circ} \mathrm{C}$, concentração de enzima de $1 \%(\mathrm{~m} / \mathrm{m})$ e razão molar água/óleo de 0,675:1 (m/m) e em shaker $\left(45^{\circ} \mathrm{C}\right.$, concentração de enzima de $0,55 \%(\mathrm{~m} / \mathrm{m})$, razão molar água/óleo de 1,35:1 (m/m)). Os autores observaram que a ação do ultrassom visivelmente acelerou a reação de hidrólise enzimática de óleo de soja em sistema livre de solvente catalisada pela lipase, e apresentou uma eficácia 2,3 vezes maior se comparado com shaker.

Huang et al. realizaram estudos comparativos de hidrólise de óleo de soja catalisada por lipase de Candida lipolytica em sistema livre de solvente, em agitador mecânico e em banho de ultrassom. Os autores constataram que o sistema de ultrassom foi mais eficaz para dispersar o óleo na água em comparação com o agitador mecânico. Além disso, também foram obtidos maior área interfacial e menor tamanho micelar no sistema de ultrassom.

Babicz et al. avaliaram a hidrólise enzimática de óleo de palma em modo batelada para a produção de diacilgliceróis usando diferentes lipases em banho de ultrassom. Os autores relataram que, em $47 \mathrm{kHz}$ e $12 \mathrm{~W}, 55^{\circ} \mathrm{C}, 700 \mathrm{rpm}$ e 90 minutos de reação, utilizando $1 \%$ de enzima (com base na massa total dos substratos), a produção total de diacilgliceróis foi de 40, 41 e 32\%, utilizando Lipozyme TL IM, Lipozyme IM e RM Novozym 435, respectivamente.

\section{CONCLUSÕES}

A tecnologia de ultrassom vem se mostrando bastante promissora para catálise enzimática em geral. Através deste trabalho ficou evidenciada sua influência em aumentar as taxas iniciais de reação no modo batelada e, consequentemente, reduzir os tempos de reação. O sistema de ultrassom é uma tecnologia limpa bastante promissora e merece o desprendimento de esforços e estudos mais aprofundados.

\section{REFERENCIAS}

ABISMAIL, B.; CANSELIER, J. P.; WILHELM, A. M.; DELMAS, H.; GOURDON, C. Emulsification by ultrasound: Drop size distribution and stability. Ultrason. Sonochem., v. 6, p. $75-83,1999$. 
AWADALLAK, J. A. Uso de ultrassom na hidrólise enzimática do óleo de palma: síntese de diacilglicerol. Dissertação de Mestrado em Engenharia Química - Universidade Estadual do Oeste do Paraná - UNIOESTE, Toledo, 2012.

BABICZ, I. Produção de diacilgliceróis via hidrólise enzimática do óleo de palma. Dissertação de Mestrado em Tecnologia de Processos Químicos e Bioquímicos - Escola de Química - EQ, Universidade Federal do Rio de Janeiro - UFRJ, Rio de Janeiro, 2009.

BABICZ, I.; LEITE, S. G. F.; SOUZA, R.; ANTUNES, O. A. C. Lipase-catalyzed diacylglycerol production under sonochemical irradiation. Ultrason. Sonochem., v. 17, p. $4-6,2010$.

DZIEZAK, J. D. Enzymes: catalyses for food processes. Food Technol., v. 45, p. 78 - 85, 1991.

HUANG, J.; LIU, Y.; SONG, Z.; JIN, Q.; WANG, X. Kinetic study on the effect of ultrasound on lipase-catalyzed hydrolysis of soy oil: study of the interfacial area and the initial rates. Ultrason. Sonochem., v. 7, p. 521 - 525, 2010.

KULDILOKE, J. Effect of ultrasound, temperature and pressure treatments on enzyme activity and quality indicators of fruit and vegetables juices. Tese de Doutorado em Ciências do Processo - Instituto de Tecnologia de Alimentos, Biotecnologia de Alimentos e Engenharia de Processos - Universidade Técnica de Berlim, Berlim, 2002.

LIU, Y.; JIN, Q.; SHAN, L.; LIU, Y.; SHEN, W.; WANG, X. The effect of ultrasound on lipase-catalyzed hydrolysis of soy oil in solvent-free system. Ultrason. Sonochem., v. 15, p. $402-407,2008$.

PATEL, R. N. Microbial/enzymatic synthesis of chiral intermediates for pharmaceutics. Enzyme Microb. Technol., v. 31, p. 804 - 826, 2002.

PIZARRO, A. V. L. e PARK, E. Y. Lipase-catalysed production of biodiesel fuel from vegetable oils contained in waste activated bleaching earth. Process Biochem., v. 38, p. 1077 - 1082, 2003.

RAMACHANDRAN, K. B.; AL-ZUHAIR, S.; FONG, C. S.; GAK, C. W. Kinetic study on hydrolysis of oils by lipase with ultrasonic emulsification. Biochem. Eng. J., v. 32, p. 19 $-24,2006$.

TREICHEL, H.; OLIVEIRA, D.; MAZUTTI, M. A.; DI LUCCIO, M.; OLIVEIRA, V. J. A review on microbial lipases production. Food Bioprocess Technol., v. 3, p. 182 - 196, 2010 . 